\title{
PENGARUH PENGGUNAAN LIMBAH ABU SEKAM PADI DAN VISCOCRETE 1003 TERHADAP KUALITAS BETON NORMAL DENGAN UPV TEST
}

\author{
Novi Rahmayanti \\ Jurusan Teknik Sipil, Fakultas Teknik Sipil dan Perencanaan, Universitas Islam \\ Indonesia \\ Email:novi.rahmayanti@uii.ac.id
}

DOI: http://dx.doi.org/10.29103/tj.v8i2.165

\begin{abstract}
Abstrak
Suatu bahan yang menggandung pozzolan seperti abu sekam padi mampu meningkatkan kekuatan tekan pada beton, tetapi dengan adanya abu sekam padi tersebut akan mempengaruhi kelecakan pada beton, sehingga digunakan bahan Viscocrete 1003 untuk meningkatkan kelecakan betonnya. Pengujian yang dapat dilakukan untuk mengetahui nilai kekuatan dan modulus elastis beton ialah pengujian destruktif . Namun pengujian ini dianggap kurang efektif karena harus merusak sample beton yang akan diuji. Pengujian dengan metode UPV dapat menjadi solusi dalam memperkirakan kuat tekan maupun modulus elastisitas beton berdasarkan nilai kecepatan rambat gelombangnya. Adapun Persentase ViscoCrete 1003 yang digunakan pada penelitian ini ialah $0,6 \%$ terhadap berat semen dan variasi penambahan abu sekam padi sebesar $0 \%, 5 \%, 10 \%, 15 \%$ dan $20 \%$ terhadap berat semen dengan benda uji silinder $15 \mathrm{~cm}$ x $30 \mathrm{~cm}$. Hasil penelitian menunjukkan bahwa nilai kuat tekan beton, kecepatan rambat gelombang dan modulus elastisitas terus meningkat hingga penambahan abu sekam sebesar $20 \%$. Modulus elastis dinamik menghasilkan nilai 39\%-45\% lebih besar dibandingkan dengan modulus elastis static dikarenakan perbedaan homogenitas pada variasi silinder.
\end{abstract}

Kata kunci: Kuat tekan, modulus elastis dinamik, abu sekam padi, Superplasticizer, upv test

\begin{abstract}
One of the pozzolan added ingredients that can increase compressive strength is rice husk ash, but the use of rice husk ash will affect the slackness of the concrete, so Viscocrete 1003 is used to increase the concrete slack. Tests that can be done to determine the strength and elastic modulus of the concrete are destructive testing. However, this test is considered to be less effective because it must damage the concrete samples to be tested. Testing with the UPV method can be a solution in estimating compressive strength and modulus of elasticity of concrete based on the value of the wave velocity. The percentage of ViscoCrete 1003 used in this study is $0.6 \%$ of the weight of cement and variations in the addition of rice husk ash by 0\%, $5 \%, 10 \%, 15 \%$ and $20 \%$ to the weight of the cement with cylindrical specimens $15 \mathrm{~cm}$ $x 30 \mathrm{~cm}$. The results showed that the value of concrete compressive strength, wave propagation velocity, and elastic modulus continued to increase until the addition of husk ash by 20\%. Dynamic elastic modulus produces a value of 39\% $-45 \%$ greater than the static elastic modulus due to differences inhomogeneity in cylinder variations.
\end{abstract}

Keywords: Compressive strength, Dynamic modulus elasticity, Rice husk ash, Superplasticizer, upv test 


\section{Latar Belakang}

Warna abu sekam padi dipengaruhi oleh jenis padi dan suhu pembakaran kulit padinya.Warna abu sekam padi dari putih keabu-abuan sampai kehitamhitaman. Sebanyak 137 juta ton per tahun abu sekam padi dihasilkan (Lim, 2012). Karakteristik beton dapat ditingkatkan dengan penambahan abu sekam padi (Xu, 2012). Ajiwe, et al (2000) di dalam (Xu, 2012) menyatakan untuk mengurangi masalah lingkungan pembuatan material semen dapat menggunakan tambahan abu sekam padi, serta tidak memerlukan proses tambahan yang dapat mengurangi emisi gas CO di atmosfir (Aprianti, 2015).

Telah ada penelitian-penelitian yang dilakukan saat ini untuk mencoba memanfaatkan bahan-bahan sisa industri yang masih memiliki karakter sebagai pozollan (Triastuti, Nugroho, A., 2017). Abu sekam padi merupakan pozzolan kelas $\mathrm{N}$ karena mengandung $\mathrm{SiO} 3+\mathrm{Al} 2 \mathrm{O} 3+\mathrm{Fe} 2 \mathrm{O} 3$ lebih dari $70 \%$ sesuai dengan mutu pozzolan kelas $\mathrm{N}$ yang disyaratkan serta memiliki kandungan silika lebih tinggi daripada blast furnace slag maupun abu terbang dan setara dengan silica fume.

Superplasticizer adalah bahan tambah kimia yang dapat melarutkan gumpalan-gumpalan dengan cara melapisi pasta semen sehingga semen dapat tersebar dengan merata dan menyelimuti agregat dengan baik serta mampu meningkatkan workability beton. Pada prinsipnya kerja superplasticizer dapat larut dalam air dan dapat menghasilkan gaya tolak-menolak antarpartikel semen agar tidak terjadi penggumpalan pada partikel semen (flocculate) yang dapat menimbulkan rongga udara dalam beton dan beton mampu mengalir tanpa terjadinya segregation dan bleeding yang umumnya terjadi pada beton dengan jumlah air yang besar. Penelitian menggunakan Visco Crete 1003 ini pernah dilakukan dengan kadar optimum yang diperoleh sebesar $0,6 \%$ dari berat semen (Sugiatmo, 2017).

Beton dibuat dan diuji untuk mengetahui karakteristiknya. Kekuatan tekan dan modulus elastisitas beton dapat diuji dengan cara destruktif dan non destruktif. Pengujian yang dilakukan dengan cara destruktif adalah cara yang paling akurat karena dilakukan pengujian langsung dengan menggunakan Compression Machine Test (CMT), akan tetapi cara pengujian ini kurang praktis dilakukan di lapangan karena harus dilakukan di laboratorium dan hingga sampelnya rusak. (Wedhanto, 2015)

Pengujian non destruktif adalah pengujian tanpa merusak sampel beton. Pelaksanaannya dapat dilakukan di lokasi pekerjaan dan dapat memperkirakan besarnya kekuatan tekan maupun modulus elastisitasnya dengan menggunakan metode Ultrasonic Pulse Velocity Test.

Kekuatan tekan beton bisa didapatkan dari kecepatan rambat gelombang elektronik longitudinal yang melalui media beton dengan melakukan pengujian UPV (International Atomic Energy Agency, Vienna, 2002). Tes UPV dapat dilakukan dalam tiga cara yaitu, langsung, semi langsung, dan tidak langsung.

Hasil penelitian ini merupakaan evaluasi awal untuk mengetahui perkiraan kualitas beton dan modulus elastisitas dengan tes UPV untuk beton dengan bahan tambah abu sekam padi dan viscocrete 1003 .

Pengaruh Penggunaan Limbah Abu Sekam Padi Dan Viscocrete 1003 Terhadap Kualitas Beton Normal Dengan Upv Test - Novi Rahmayanti 


\section{Metode Penelitian}

\subsection{Bahan}

Beton pada penelitian ini terdiri dari semen PPC merk tiga roda, pasir merapi, kerikil clereng, abu sekam padi, air, dan viscocrete 1003. abu sekam padi yang digunakan merupakan sisa pembakaran bata yang lolos saringan No. 200 dan tidak terukur suhu pembakarannya. Persentase abu sekam padi yang digunakan sebagai bahan tambah pada penelitian ini adalah $0 \%, 5 \%, 10 \%, 15 \%$, dan $20 \%$ terhadap berat semen dengan abu sekam. Agregat kasar dan halus yang digunakan memiliki ukuran maksimal $20 \mathrm{~mm}$ dan $4,75 \mathrm{~mm}$, akan tetapi tidak lolos saringan No. 200 dan dalam kondisi SSD. viscocrete 1003 digunakan untuk meningkatkan workability dengan persentase yang digunakan adalah sebesar $0,6 \%$ dari berat semen.

\subsection{Metodologi}

Rencana mutu beton pada penelitian ini adalah $25 \mathrm{MPa}$, dengan nilai fas 0,5. Adapun proporsi campuran beton dapat dilihat pada Tabel 1. Beton dengan kode S0 merupakan beton pembanding untuk kode beton yang lain. Pada penelitian ini dilakukan pengujian kuat desak beton dan modulus elastisitas statik dengan CMT dan kecepatan rambat gelombang untuk memperkirakan nilai kuat desak serta modulus dinamik dengan UPV tes. Benda uji yang digunakan pada penelitian ini ada benda uji silinder standar berdiameter $15 \mathrm{~cm}$ dan tinggi $30 \mathrm{~cm}$ dengan beton dirawat selama 28 hari kemudian dilakukan pengujian dengan UPV dan CMT.

Adapun tahapan yang dilakukan dalam pembuatan benda uji ialah pertamatama pasir, kerikil diaduk, kemudian dimasukkan abu sekam padi, dan dilanjutkan dengan memasukkan semen hingga adukan menjadi homogen dengan menggunakan mixer. Setelah itu masukkan air sedikit demi sedikit hingga $3 / 4$ kebutuhannya kedalam adukan dan masukkan viscocrete perlahan-lahan hingga viscocrete habis, kemudian masukkan sisa air sedikit demi sedikit. Pada penelitian ini tidak ada pengurangan air.

Tabel 1. Komposisi bahan

\begin{tabular}{lclllll}
\hline \multicolumn{7}{c}{ Bahan } \\
\hline Kode & $\begin{array}{c}\text { Semen } \\
(\mathbf{k g})\end{array}$ & $\begin{array}{c}\text { Abu sekam } \\
\text { padi }(\mathbf{k g})\end{array}$ & $\begin{array}{c}\text { Air } \\
(\mathbf{k g})\end{array}$ & $\begin{array}{c}\text { Agregat } \\
\text { halus }(\mathbf{k g})\end{array}$ & $\begin{array}{c}\text { Agregat } \\
\text { kasar }(\mathbf{k g})\end{array}$ & $\begin{array}{c}\mathbf{S P} \\
(\mathbf{k g})\end{array}$ \\
\hline $\mathbf{S}_{\mathbf{0}}$ & 13,035 & 0 & 6,517 & 23,155 & 32,641 & 0,078 \\
\hline $\mathbf{S}_{\mathbf{5}}$ & 13,035 & 0,652 & 6,517 & 23,515 & 32,641 & 0,078 \\
\hline $\mathbf{S}_{\mathbf{1 0}}$ & 13,035 & 1,303 & 6,517 & 23,515 & 32,641 & 0,078 \\
\hline $\mathbf{S}_{\mathbf{1 5}}$ & 13,035 & 1,955 & 6,517 & 23,515 & 32,641 & 0,078 \\
\hline $\mathbf{S}_{\mathbf{2 0}}$ & 13,035 & 2,607 & 6,517 & 23,515 & 32,641 & 0,078 \\
\hline
\end{tabular}

Kuat tekan beton adalah besarnya beban per satuan luas yang menyebabkan benda uji beton hancur bila dibebani gaya tekan tertentu yang dihasilkan oleh mesin tekan (CMT). Berdasarkan SNI 1974-2011, nilai kuat tekan yang muncul dapat dihitung dengan Persamaan 1. 


$$
f^{\prime} c=\frac{P}{A}
$$

Keterangan:

$$
\begin{aligned}
f^{i} c & =\text { Kuat tekan beton }(\mathrm{MPa}) \\
P & =\text { Beban Maksimum }(\mathrm{N}), \\
A & =\text { Luas penampang benda uji }\left(\mathrm{mm}^{2}\right) .
\end{aligned}
$$

Modulus elastisitas statis yang dilakukan dengan mesin CMT pada umumnya kurva regangan dan tengangan yang terjadi pada beton saat nilai $40 \%$ dari f'c dianggap dalam kondisi yang linier dan sesudah mendekati $70 \%$ tegangan hancur, pada saat kondisi hancur material banyak kehilangan kekakuannya sehingga menjadikan kurva tidak linier. Modulus elastisitas dapat dihitung menggunakan rumus ASTM C-469 sebagai berikut.

$$
E c=\frac{S_{2}-S_{1}}{\varepsilon_{2}-0,000050}
$$

\section{Keterangan:}

$\mathrm{Ec}=$ Modulus elastisitas beton $(\mathrm{MPa})$,

$\mathrm{S}_{2}=$ Kuat tekan pada saat $40 \%$ dari beban maksimum (MPa),

$\mathrm{S}_{1}=$ Kuat tekan pada saat regangan longitudinal mencapai

$\varepsilon_{1}=0,000005$,

$\varepsilon_{2}=$ Regangan longitudinal yang dihasilkan pada saat $S_{2}$.

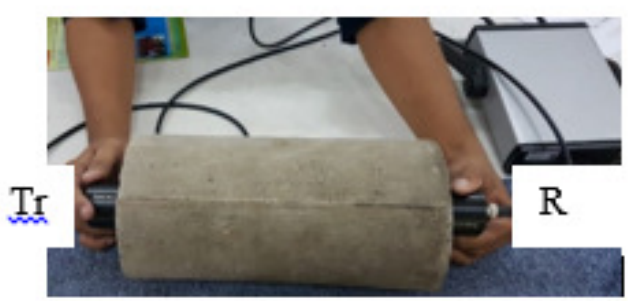

Gambar 1 Cara pengukuran dengan UPV (langsung)

Alat tes UPV bekerja dengan cara memberi getaran gelombang longitudinal dari tranduser ( $\mathrm{Tr}$ ) yang kemudian gelombang akan diterima oleh Reciver (R). Gelombang geser merambat tegak lurus lintasan, dan gelombang longitudinal merambat sejajar lintasan (wedhanto, 2015). Pertama kali yang mencapai tranduser penerima $(\mathrm{R})$ adalah gelombang longitudinal. Oleh tranduser, gelombang ini diubah menjadi sinyal gelombang elektronik yang dapat dideteksi oleh tranduser penerima, sehingga waktu tempuh gelombang dapat diukur. Pengujian cepat rambat gelombang pada penelitian ini dilakukan dengan cara langsung seperti yang terlihat pada gambar 1 .

Waktu tempuh $\mathrm{T}$ yang dibutuhkan untuk merambatkan gelombang pada lintasan beton sepanjang L dapat diketahui, sehingga kecepatan gelombang dapat dicari dengan persamaan 3 . 


$$
V=\frac{L}{T}
$$

Keterangan:

$V=$ Kecepatan rambat gelombang $(\mathrm{m} / \mathrm{s})$,

$\mathrm{L}=$ Jarak antara pusat permukaan tranduser $(\mathrm{m})$,

$\mathrm{T}=$ Waktu tempuh gelombang (s).

Kecepatan rambat gelombang melalui beton atau ultrasonic pulse velocity test (UPV) dilakukan untuk mengindikasikan adanya rongga atau retak pada beton, sehingga akan diketahui tingkat homogenitas atau kepadatan dari beton, dengan kata lain kualitas beton dapat diprediksi seperti yang terlihat di Tabel 2.

Tabel 2 Kualitas Beton Berdasarkan UPV Test

\begin{tabular}{cl}
\hline $\begin{array}{c}\text { Kecepatan Gelombang Longitudinal } \\
(\mathbf{k m} / \mathbf{d t})\end{array}$ & Kualitas Beton \\
\hline$>4,5$ & Sangat bagus \\
\hline $3,50-4,50$ & Bagus \\
\hline $3,00-3,50$ & Diragukan \\
\hline $2,00-3,00$ & Jelek \\
\hline$<2,00$ & Sangat jelek \\
\hline
\end{tabular}

(Sumber: International Atomic Energy Agency, Vienna, 2002)

Faktor-faktor yang mempengaruhi kepadatan beton antara lain gradasi agregat, proposi campuran dan kejenuhan air dalam beton. SNI 03-4802-1998 menyatakan kecepatan rambat gelombang pada beton yang jenuh air membuat pengujian ini menjadi kurang sensitif terhadap perubahan mutu beton.

Modulus elastis dinamik dapat diperhitungkan dengan menghubungkan nilai kecepatan rambat gelombang, poisson ratio dan massa jenis beton dengan menggunakan persamaan 4 berikut. Purwanto dan ro'uf (2018) meneliti pengujian modulus elastis dinamis dan modulus statis yang menghasilkan nilai modulus elastis dinamis yang sebanding dan lebih tinggi $45 \%$ - $249 \%$ dari pengujian modulus elastis statis.

$$
E=V^{2} \frac{\rho(1+\mu)(1-2 \mu)}{(1-\mu)}
$$

Keterangan:

$\mathrm{E}=$ adalah nilai modulus elastisitas dinamis $(\mathrm{MPa})$,

$\mathrm{V}=$ kecepatan rambat gelombang ultrasonic $(\mathrm{km} / \mathrm{s})$,

$\rho=$ kepadatan beton atau perbandingan massa dengan volume beton $\left(\mathrm{kg} / \mathrm{m}^{3}\right)$,

$\mu=$ poisson ratio dinamis.

Nilai poisson ratio untuk kekuatan beton dengan nilai kuat tekan berada di bawah 19,5 MPa memiliki nilai poisson ratio 0,26. Beton yang memiliki nilai kuat tekan diantara 19,5 MPa dan 76,5 MPa memiliki nilai rasio poisson sebesar 0,23. 
Pada beton yang memiliki nilai kuat tekan di atas 76,5 MPa memiliki nilai rasio poisson sebesar 0,18 (Yildirim dan Sengul, 2011).

\section{Hasil dan Pembahasan}

\subsection{Pengujian Kuat Tekan Beton CMT}

Pengujian kuat desak beton dilakukan dengan menggunakan mesin uji desak merk ELE3000. Pengujian ini termasuk pengujian destruktif. Kuat tekan beton mengidentifikasikan mutu dari campuran. Semakin baik mutu campuran, maka nilai kuat tekan semakin meningkat. Hubungan kuat tekan beton dengan variasi penambahan abu sekam padi dapat dilihat pada Tabel 3.

Hasil pengujian menunjukkan bahwa penggunaan viscocrete 1003 dengan penambahan abu sekam padi sampai dengan $20 \%$ dari berat semen yaitu pada silinder $\mathrm{S}_{20}$ masih mampu meningkatkan mutu dan nilai kuat desak beton.

Hasil penelitian ini berbeda dengan yang dilakukan oleh Rosida dkk (2008) yang menyatakan bahwa penambahan abu sekam padi optimum pada kadar $15 \%$. Hal ini dikarenakan abu sekam padi yang digunakan pada penelitian ini tidak diketahui jenis sekam padinya serta suhu dan lamanya pembakaran.

Tabel 3 Hasil pengujian Kuat Desak Beton

\begin{tabular}{|c|c|c|c|}
\hline $\begin{array}{c}\text { Kode } \\
\text { Silinder }\end{array}$ & $\begin{array}{c}\text { Prosentase } \\
\text { Abu Sekam }\end{array}$ & $\begin{array}{c}\text { Kuat Tekan } \\
\text { (Мpa) }\end{array}$ & $\begin{array}{c}\text { Kuat Tekan Rerata } \\
\text { (Mpa) }\end{array}$ \\
\hline \multirow{3}{*}{ So } & \multirow{3}{*}{$0 \%$} & 25.182 & \multirow{3}{*}{26.230} \\
\hline & & 28.102 & \\
\hline & & 25.408 & \\
\hline \multirow{3}{*}{$\mathrm{S}_{5}$} & \multirow{3}{*}{$5 \%$} & 29.387 & \multirow{3}{*}{30.756} \\
\hline & & 29.197 & \\
\hline & & 33.683 & \\
\hline \multirow{3}{*}{$\mathrm{S}_{10}$} & \multirow{3}{*}{$10 \%$} & 31.543 & \multirow{3}{*}{32.646} \\
\hline & & 34.135 & \\
\hline & & 32.260 & \\
\hline \multirow{3}{*}{$\mathrm{S}_{15}$} & \multirow{3}{*}{$15 \%$} & 32.084 & \multirow{3}{*}{33.766} \\
\hline & & 35.509 & \\
\hline & & 33.705 & \\
\hline \multirow{3}{*}{$\mathrm{S}_{20}$} & \multirow{3}{*}{$20 \%$} & 32.997 & \multirow{3}{*}{34.112} \\
\hline & & 35.320 & \\
\hline & & 34.018 & \\
\hline
\end{tabular}

Analisis regresi pada gambar 2 dilakukan untuk mendapatkan gambaran antara abu sekam padi dan kuat tekan. Dari persamaan regresi dapat terlihat bahwa nilai plus pada koefisien regresi menunjukkan peningkatan nilai kuat tekan seiring dengan penambahan presentase penggunaan abu sekam padi.

Pengaruh Penggunaan Limbah Abu Sekam Padi Dan Viscocrete 1003 Terhadap 


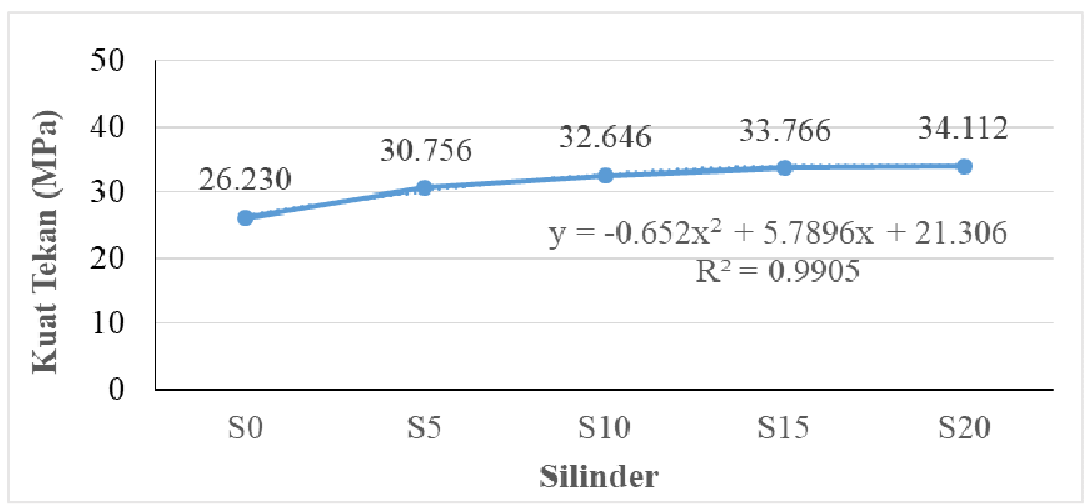

Gambar 2 Hasil Pengujian Kuat Tekan Beton Rata-Rata

\subsection{Pengujian Kecepatan Rambat Gelombang Beton dengan UPV Test}

Pengujian UPV akan menghasilkan nilai berupa travel time, kemudian dilakukan perhitungan velocity. Pengujian ini dilakukan pada silinder beton secara direct yang dilakukan terhadap 3 titik tranducer dan reciver untuk masing-masing silinder. Adapun hasil pengujiannya disajikan pada Tabel 4 berikut ini.

Tabel 4 Kecepatan rambat gelombang dengan menggunakan UPV Test

\begin{tabular}{cccccc}
\hline Kode & $\begin{array}{c}\text { Jarak } \\
(\mathbf{m})\end{array}$ & $\begin{array}{c}\text { Waktu } \\
(\mathbf{s})\end{array}$ & $\begin{array}{c}\text { Kecepatan } \\
(\mathbf{k m} / \mathbf{s})\end{array}$ & $\begin{array}{c}\text { Kecepatan } \\
\mathbf{R e r a t a} \\
(\mathbf{k m} / \mathbf{s})\end{array}$ & Kualitas Beton \\
\hline $\mathbf{S}_{\mathbf{0}}$ & 0,3064 & $67,2.10-6$ & 4,560 & & Sangat bagus \\
& 0,3044 & $64,1.10-6$ & 4,749 & 4,648 & Sangat bagus \\
& 0,3031 & $65,4 \cdot 10-6$ & 4,635 & & Sangat bagus \\
\hline $\mathbf{S}_{\mathbf{5}}$ & 0,3073 & $65,4 \cdot 10-6$ & 4,699 & & Sangat bagus \\
& 0,3054 & $63,4 \cdot 10-6$ & 4,817 & 4,741 & Sangat bagus \\
& 0,3054 & $64,9 \cdot 10-6$ & 4,706 & & Sangat bagus \\
\hline $\mathbf{S}_{\mathbf{1 0}}$ & 0,3039 & $63,9 \cdot 10^{-6}$ & 4,756 & & Sangat bagus \\
& 0,305 & $62,4 \cdot 10^{-6}$ & 4,888 & 4,803 & Sangat bagus \\
& 0,3045 & $63,9 \cdot 10^{-6}$ & 4,765 & & Sangat bagus \\
\hline $\mathbf{S}_{\mathbf{1 5}}$ & 0,302 & $62,9 \cdot 10-6$ & 4,801 & & Sangat bagus \\
& 0,3015 & $63,9 \cdot 10-6$ & 4,718 & 4,820 & Sangat bagus \\
& 0,3058 & $61,9 \cdot 10-6$ & 4,940 & & Sangat bagus \\
\hline $\mathbf{S}_{\mathbf{2 0}}$ & 0,302 & $62,9 \cdot 10-6$ & 4,801 & & Sangat bagus \\
& 0,3005 & $61,6 \cdot 10-6$ & 4,878 & 4,845 & Sangat bagus \\
& 0,3029 & $62,4 \cdot 10-6$ & 4,854 & & Sangat bagus \\
\hline
\end{tabular}

Pengaruh Penggunaan Limbah Abu Sekam Padi Dan Viscocrete 1003 Terhadap Kualitas Beton Normal Dengan Upv Test - Novi Rahmayanti 
Berdasarkan Tabel 4, dapat dilihat bahwa kualitas beton berada dalam kondisi sangat bagus untuk semua variasi dan nilai kecepatan rambat gelombang tertinggi berada pada vasiasi silinder $S_{20}$ yaitu $4,845 \mathrm{~km} / \mathrm{s}$ dan terendah berada pada variasi $\mathrm{S}_{0}$ yaitu $4,648 \mathrm{~km} / \mathrm{s}$. Kecepatan rambat gelombang ultrasonik pada beton akan dipengaruhi oleh kepadatan dan kehomogenitasan beton. Makin padat dan makin homogen suatu beton, waktu tempuh gelombang yang diperlukan makin pendek sehingga kecepatannya meningkat dan sebaliknya jika betonnya terdapat rongga maka waktu yang diperlukan semakin lama sehingga kecepatannya menurun (ma'arif dkk, 2011). Hal ini berarti penambahan abu sekam padi akan membuat beton lebih padat dan meningkat nilai kuat tekannya dalam persentase penambahan tertentu karena abu sekam padi mampu mengisi rongga yang ada pada beton.

Besarnya variasi abu sekam padi akan menimbulkan kerapatan yang berbeda terhadap homogenitas campuran beton segar. Penggunaan abu sekam padi secara proporsional dapat dikaji melalui uji berat volume silinder dan kecepatan rambat gelombang yang tersaji pada gambar ini. Penggunaan abu sekam padi dengan pembakaran tidak terkontrol masih mampu mengisi rongga-rongga pada beton hingga penambahan $20 \%$ terhadap berat semen $\left(S_{20}\right)$ seperti yang ditunjukan pada gambar 3 yang merupakan hasil pengujian kecepatan rambat gelombang dan berat volume yang nilainya terus meningkat.

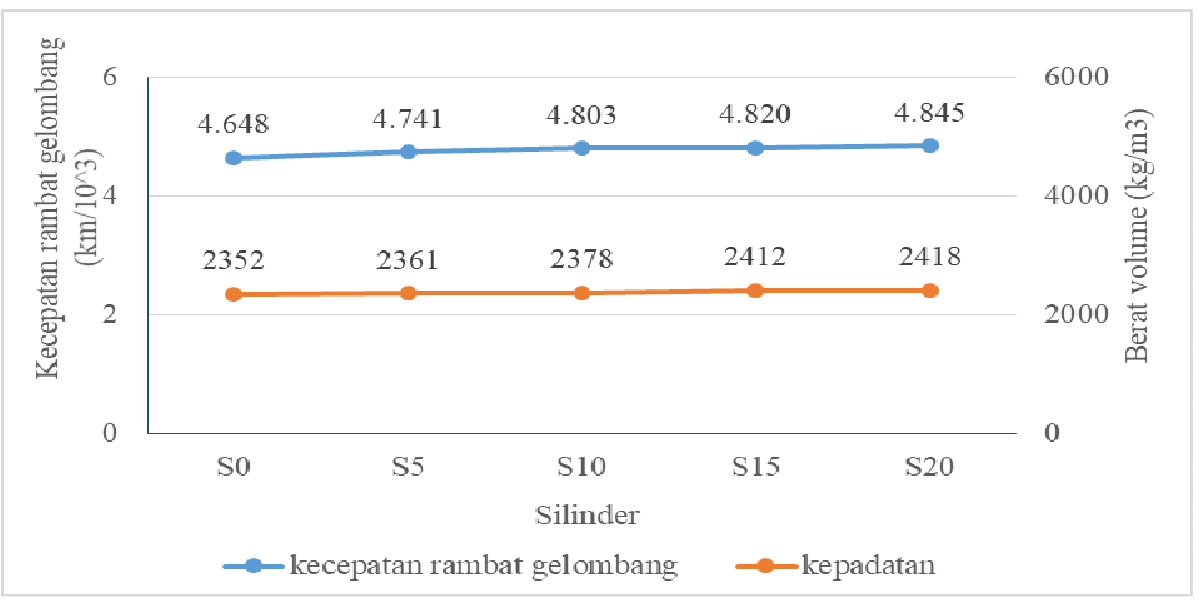

Gambar 3 Hasil pengujian kecepatan rambat gelombang dan berat volume silinder beton

Grafik berat volume diatas membentuk garis yang meningkat tapi landai yang menandakan penambahan abu sekam padi hanya sedikit menambah berat isi silinder beton. Hal ini dikarenakan berat isi abu sekam lebih kecil dibandingkan dengan material lainnya (rosida dkk, 2008).

\subsection{Pengujian Modulus Elastisitas}

Nilai modulus beton bergantung pada variasi kekuatan beton, umur beton, jenis pembebanan dan karakteristik serta perbandingan antara semen dengan agregat. modulus elastis dinamik dihitung berdasarkan persamaan 4 dengan menggunakan nilai poisson ratio sebesar 0,23. 
Nilai poisson ratio ditetapkan berdasarkan nilai kuat tekan yang diperoleh dari Tabel 3. Nilai kepadatan dan kecepatan rambat gelombang menggunakan hasil pengujian Gambar 3, sedangkan nilai modulus statik diperoleh dari hasil pengujian dengan mesin desak berdasarkan hubungan tegangan-regangan yang hasilnya diolah dengan persamaan 2 .

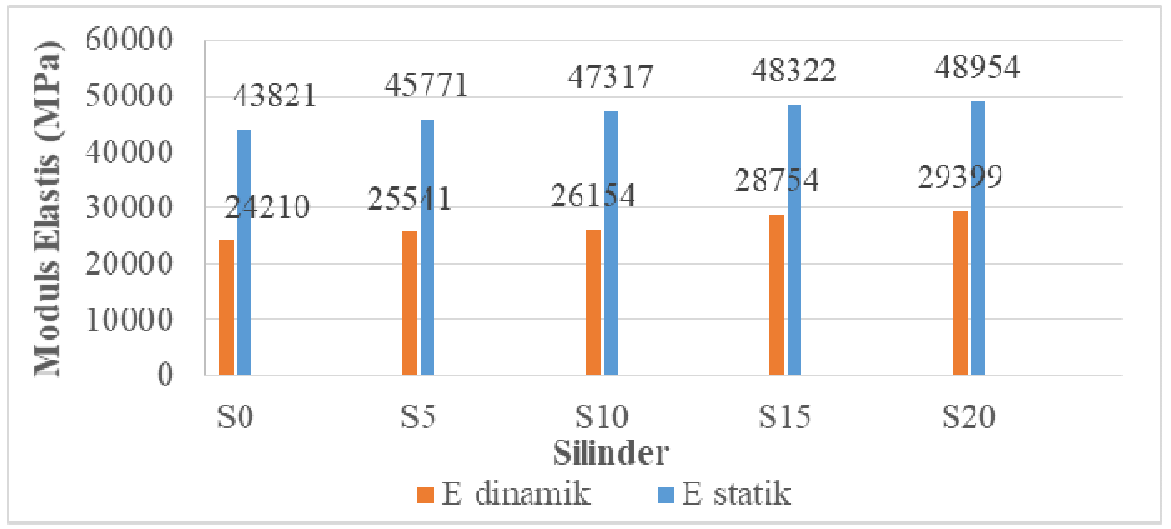

Gambar 4 Nilai modulus elastis dinamik dan modulus elastis statis.

Berdasarkan gambar 4 terlihat bahwa pengujian modulus elastis dinamik menghasilkan nilai yang lebih besar $39 \%-45 \%$ dari pada pengujian modulus elastis statik. Hal ini dikarenakan perhitungan modulus dinamik ditentukan oleh pengukuran kecepatan rambat gelombang. Nilai kecepatan rambat gelombang tersebut dipengaruhi oleh homogenitas beton (Lee et.al, 2017).

\section{Kesimpulan dan Saran}

\subsection{Kesimpulan}

Berdasarkan analisis yang telah dilakukan dan pembahasan yang telah diuraikan pada, maka dapat diambil kesimpulan dari penelitian ini sebagai berikut. 1. Nilai kuat tekan beton terus meningkat dan kualitas beton sangat bagus hingga penambahan $20 \%$ abu sekam padi dengan $0,6 \%$ viscocrete 1003 .

2. Kecepatan rambat gelombang dan berat volume beton meningkat seiring dengan peningkatan persentase penggunaan abu sekam padi. Hal ini berarti abu sekam padi mengisi rongga-rongga yang ada pada beton.

3. Nilai modulus elastis dinamik lebih besar $39 \%$ - $45 \%$ daripada modulus elastis statik dikarenakan perbedaan homogenitas beton.

\subsection{Saran}

Berdasarkan kesimpulan dari hasil penelitian yang telah dilakukan dapat menjadi saran untuk penelitian selanjutnya untuk mendapatkan hasil yang lebih baik yaitu dilakukan penelitian lanjutan untuk mengetahui pengaruh penambahan abu sekam padi lebih dari $20 \%$ terhadap karakteristik beton. 


\section{Daftar Kepustakaan}

Aprianti, Evi, Payam, Shafigh., Syamsul, Bahri., and Javad, Nodeh Farahani, 2015, Supplementary Cementitious Materials Origin from Agricultural Wastes - A Review, Construction and Building Materials 74(April):176-87.

Badan Standarisasi Nasional. 1998. SNI 03-4802-1998: Metode Kecepatan Pulsa Melalui Beton. BSN. Jakarta.

Badan Standarisasi Nasional. 2011. SNI 03-1974-2011: Cara Uji Kuat Tekan Beton dengan Benda Uji Silinder yang Dicetak. BSN. Jakarta.

International Atomic Energy Agency, Vienna. 2002. Guidebook on non destructive testing of concrete structures. Training Course Series No. 17.

Lee, B.J., Kee, S.H., Oh, T., Kim, Y.Y., 2017, Evaluating the Dynamic Elastic Modulus of Concrete Using Shear-Wave Velocity Measurements. Hindawi, Advances in Materials Science and Engineering. Vol 2017

Lim, J.S., Manan, Z.A., Alwi, S.R.W., Hashim, H., 2012, A Review On Utilization Of Biomassa From Rice Industry As A Source Of Renewable Energy. Renew. Sustainable Energy Rev . 16, 3084-3094.

Ma'arif, F., Widodo, S., Santoso, A., 2011, Analisis Homogenitas Self Compacting Mortar Menggunakan Serat Polypropylene Berdasarkan Kecepatan Perambatan Gelombang Ultrasonik (UPVM), Jurnal INERSIA, Vol. VII, No. 2, Desember 2011.

Purwanto, P., dan Ro’uf A., 2018, Sistem Pengukuran Modulus Elastisitas Beton Menggunakan Metode Ultrasonic Pulse Velocity, Indonesian Journal of Electronicsand Instrumentation Systems (IJEIS), Vol. 8, No. 1, April 2018.

Rosida, E., Puri, A., Masrizal, 2008.,Pengaruh Penggunaan Bahan Tambahan Abu Sekam Padi Terhadap Kuat Tekan dan Workabilitas Beton. Jurnal Saintis Vol.10 No.1: 1-10. Riau

Sugiatmo, D., Solikin, M., Ir H Ali Asroni, M.T., 2017. Sifat Mekanis Pada Beton Self Compacting Concrete Dengan Menggunakan Bahan Tambah Viscocrete 1003 Dan Viscoflow 3211 N. Universitas Muhammadiyah Surakarta. Surakarta.

Triastuti dan Nugroho A., 2017, Pengaruh Penggunaan Abu Sekam Padi terhadap Sifat Mekanik Beton Busa Ringan, Jurnal Teknik Sipil ITB, Vol 24 No 2 Agustus. Hal 139-143.

Wedhanto, S., 2015, Penggunaan Metode Ultrasonic Pulse Velocity Test Untuk Memperkirakan Kekuatan Dan Keseragaman Mutu Beton K 200 Secara Non Destruktif, Jurnal Banguan, Vol. 20, No. 1, Desember 2015.

Xu, W., Lo, T.Y., Memon, S.A., 2012, Microstructure and reactivity of rice husk ash. Construction and Building Materials, 29, 541-547.

Yildirim, H. and Sengul O., 2011, Modulus of Elasticity Of Substandard And Normal Concretes, Construction Building Material, vol. 25, no.4, pp. 16451652, 2011, J., Kirkby, M.J., Lane, S.N., Milledge, D.G., Brookes, C.J., Holden, V., McDonald, A.T., 2008. Overland flow velocity and roughness properties in peatlands. Water Resour. Res. 44.

Pengaruh Penggunaan Limbah Abu Sekam Padi Dan Viscocrete 1003 Terhadap 